\title{
Burnout Ditinjau Dari Kualitas Kehidupan Kerja Pada Karyawan
}

\author{
Fendro Chandra, Rianda Elvinawanty \\ Unviersitas Prima Indonesia \\ Email: fendrotjandra@unprimdn.ac.id
}

\begin{abstract}
This study aims to determine the relationship between quality of work life and burnout. Subjects used in this study were Workers at PT Multi Sarana Medanv consisting of 94 people who were selected by using purposive sampling technique. Data were obtained from a scale to measure quality of worklife and burnout. The calculation was performed by means of testing requirements analysis (assumption test) that consists of a test for normality and linearity. Analysis of the data used was performed by Product Moment Analysis through SPSS 17 for Windows. The results of data analysis showed that $r=-0,839$ and $p=0.000(p<0.05)$, indicating that there was a positive relationship between burnout and turnover intention. The results of this study indicated that the contribution $\left(R^{2}\right)$ given to the quality of worklife to burnout intention was $70.3 \%$, the remaining $29.7 \%$ were affected by other factors not examined.
\end{abstract}

Keywords: burnout, kualitas kehidupan kerja, karyawan

\begin{abstract}
Abstrak
Penelitian ini bertujuan untuk mengetahui hubungan antara kualtas kehidupan kerja dan burnout. Subjek penelitian yang digunakan dalam penelitian ini adalah karyawan pada PT Multi Sarana Medan, sebanyak 94 orang yang dipilih dengan menggunakan purposive sampling. Perhitungan dilakukan dengan melalui uji prasyarat analisis (uji asumsi) yang terdiri dari uji normalitas dan uji linearitas. Analisis data yang digunakan adalah menggunakan Analisa Product Moment melalui bantuan SPSS 17 for Windows. Hasil analisis data menunjukkan $\mathrm{r}=-0.839$, dan $\mathrm{p}=0.000(\mathrm{p}<0.05)$ yang menunjukkan bahwa terdapat hubungan negatif antara kualitas kehidupan kerja dan burnout. Hasil penelitian ini menunjukkan bahwa sumbangan $\left(\mathrm{R}^{2}\right)$ yang diberikan variable kualitas kehidupan kerja terhadap burnout adalah sebesar 70.9 persen, selebihnya 29.7 persen dipengaruhi oleh faktor lain yang tidak diteliti
\end{abstract}

Kata kunci: burnout, kualitas kehidupan kerja, karyawan

\section{Pendahuluan}

Pada era globalisasi ini, persaingan antar perusahaan semakin tinggi dan semakin kompleks oleh karena itu setiap perusahaan dituntut untuk memperbaiki hal-hal yang terkait dalam setiap perusahaan dan lebih responsif agar dapat terus bertahan dan terus berkembang. Sumber daya manusia dalam suatu perusahaan merupakan unsur paling penting yang harus dimiliki suatu perusahaan atau organisasi sehingga memperoleh perhatian khusus dari manajemen perusahaan (Hariandja, 2002). Karyawan sering diminta berkeja secara optimal bahkan perusahaan sering sekali menuntut karyawan untuk dapat bekerja melebihi dari waktu kerja yang sebenarnya atau yang sudah ditetapkan sebelumnya oleh perusahaan. Hal tersebut mengakibatkan setiap karyawan lebih banyak menghabiskan waktunya untuk bekerja dan sulit memiliki waktu senggang untuk beristirahat ataupun untuk refreshing. Selain bekerja melebihi waktu kerja yang sebenarnya, ditambah tekanan dari atasan maupun dari teman kerja, dan juga beban kerja yang berlebih menyebabkan karyawan mengalami sindrom kelelahan baik fisik maupun emosional. Banyaknya perusahaan di zaman ini yang terus menuntut setiap karyawan agar dapat bekerja secara maksimal dan bekerja melebihi waktu kerja yang sebenarnya menyebabkan kasus kelelahan fisik dan mental seperti pada kasus berikut ini. Meritha (26 tahun), seorang perempuan pekerja di sebuah bank BRI, ditemukan tewas di suatu selokan air dekat Thamrin City, di Jakarta Pusat. Meritha diduga tewas setelah terjun bebas dari area parkiran dari lantai 10. Hal tersbut diduga bahwa ia mengalami stres pada pekerjaannya sehingga ia memutuskan untuk mengakhiri hidupnya sendiri (www. koran-sindo.com). Berdasarkan survei dan hasil wawancara yang dilakukan terhadap karyawan di PT. Multi Sarana menunjukan bahwa terdapat beberapa karyawan yang merasakan tekanan yang sangat kuat dari atasannya sendiri. Banyaknya pekerjaan yang diberikan tidak sesuai dengan pekerjaan utama juga. Setiap karyawan juga sering bekerja melebihi jam kerja yang seharusnya, beberapa hal tersebut lama kelemaan menyebabkan mereka mulai merasa lelah, baik fisik maupun emosional dan terdapat karyawan yang sering merasa sakit kepala dan mual, bahkan ada yang mulai menghindar dan tidak terlalu peduli atau mengabaikan pekerjaan yang bukan pekerjaan utamanya sendiri. 
Berdasarkan hasil wawancara dan survei di PT Multi Sarana dapat dilihat bahwa karyawan di perusahaan tersebut yang terkena sindrom burnout. Menurut Maslach dan Leiter (1997) menjelaskan bahwa bekerja secara berlebihan atau work overload merupakan faktor utama yang mendasari seorang karyawan dapat mengalami burnout. Burnout sebagai sebuah tahap kelelahan fisik, emosional dan mental yang disebabkan oleh keterlibatan jangka panjang dalam situasi yang penuh dengan tuntutan emosional oleh Pines dan Aronson (dalam Schabracq, dkk., 2003). Salah satu faktor yang menyebabkan burnout menurut Tuuli dan Karisalmi (2010) adalah kualitas kehidupan kerja atau quality of work life. Kualitas kehidupan kerja seorang karyawan sangat penting dan harus diperhatikan oleh setiap perusahaan, baik dalam upah dan jaminan kerja harus memadai dengan pekerjaan yang telah dihasilkan oleh si karyawan sehingga bila hal-hal tersebut dipenuhi maka kualitas kehidupan kerja seorang karyawan akan tinggi, maka karyawan tersebut akan tetap semangat mengerjakan pekerjaan yang ada, walaupun beban kerja yang diberikan cukup banyak, akan tetapi hasil yang di berikan oleh perusahaan sebanding sehingga si tenaga kerja akan sulit mengalami burnout. Hal ini menggambarkan apabila kualitas kehidupan kerja seorang karyawan tinggi maka si karyawan tersebut akan sulit terkena burnout. Berdasarkan hasil kajian literatur yang ada, terdapat peneliti yang telah melakukan penelitian untuk menunjukan adanya hubungan antara kualitas kehidupan kerja terhadap burnout. Salah satu penelitian yang dilakukan oleh Habibah dan Lubis (2015) di terhadap karyawan di PT. Surya Alam Permai yang berjumlah 80 karyawan menunjukan hasil bahwa kualitas kehidupan kerja memiliki hubungan negatif yang sangat signifikan. Artinya apabila semakin tinggi kualitas kehidupan kerja, artinya organisasi tersebut dapat memberikan kemanan dalam bekerja, gaji yang lebih baik, kesempatan untuk mengembangkan diri, dan meningkatkan produktivitas organisasi maka individu mengalami burnout akan semakin rendah. Sebaliknya apabila karyawan memiliki kualitas kehidupan kerja yang rendah maka akan semakin tinggi individu mengalami burnout. Berdasarkan uraian di atas dan fenomena-fenomena yang berkaitan dengan adanya penurunan kualitas kehidupan kerja di beberapa perusahaan yang disebabkan oleh burnout maka peneliti tertarik untuk mengadakan penelitian dengan judul penelitian "Burnout Ditinjau Dari Kualitas Kehidupan Kerja Pada Karyawan Di PT. Multi Sarana Medan”. Tujuan dari penelitian ini ialah untuk mengetahui hubungan antara kualitas kehidupan kerja dengan burnout.

\section{Metode Penelitian}

Identifikasi variabel diperlukan untuk menentukan metode dan alat yang dipakai dalam pengumpulan data. Adapun variabel-variabel yang digunakan pada penelitian ini yaitu burnout sebagai variabel tergantung dan kualitas kehidupan kerja sebagai variabel bebas. Menurut Arikunto (2010), populasi adalah keseluruhan dari subjek penelitian.Hal yang sama juga diungkapkan oleh Soewadji (2012), populasi adalah sekelompok orang, kejadian atau segala sesuatu yang memiliki karakteristik tertentu. Populasi dalam penelitian ini adalah karyawan yang telah bekerja di atas 3 tahun dan memiliki umur lebih dari 25 tahun yang bekerja di PT. Multi Sarana Medan yang berjumlah 94 karyawan. Menurut Martono (2011) sampel merupakan bagian dari populasi yang memiliki ciri-ciri atau keadaan tertentu yang akan diteliti. Selanjutnya Aikunto (2010) menyatakan bahawa apabila dalam pengambilan sampel dapat dilakukan dengan mengambil semuanya sehingga penelitiannya merupakan penelitian populasi, maka teknik sampling dalam penelitian ini menggunakan teknik total sampling atau sampling jenuh. Alat pengumpul data yang digunakan dalam penelitian ini adalah dengan menggunakan metode skala. Skala menurut Azwar (2006) memiliki karakteristik khusus yang membedakannya dari berbagai bentuk alat pengumpulan data yang lain seperti angket, daftar isian, inventori, dan lainnya. Penelitian ini menggunakan dua skala yaitu skala burnout dan kualitas kehidupan kerja. Skala burnout disusun berdasarkan aspek yang dikemukakan oleh Maslach (dalam Vandenberghe \& Huberman, 2006) yaitu: emotional exhaustion, depersonalization, reduced personal accomplishment. Skala ini disusun berdasarkan aspek yang dikemukakan Ventegodt dan Merrick (2009) diantaranya: kesehatan dan kesejahteraan, keamanan kerja, kepuasan kerja, kompetensi pembangunan dan keseimbangan antara pekerja dan kehidupan di luar pekerja. Kedua skala ini disajikan dalam bentuk pernyataan yang bersifat favourable dan unfavourable dengan empat alternatif jawaban untuk setiap empat butir pernyataan. Kriteria penilaian aitem favourable berdasarkan skala likert adalah nilai 1 (satu) untuk jawaban (STS), nilai 2 (dua) untuk jawaban (TS), nilai 3 (tiga) untuk jawaban (S), dan nilai 4 (empat) untuk jawaban (SS). Sedangkan untuk item unfavourable, nilai (1) untuk jawaban (SS), nilai 2 (dua) untuk jawaban (S), nilai 3 (tiga) untuk jawaban (TS), nilai 4 (empat) untuk jawaban STS yang disebut dengan skala likert. Jenis validitas yang digunakan dalam penelitian ini adalah validitas isi. Validitas isi merupakan validitas yang diestimasi lewat pengujian terhadap isi tes dengan analisis rasional atau lewat professional judgement. Pertanyaan yang dicari jawabannya dalam validasi ini adalah sejauh mana aitem-aitem tes mewakili komponen-komponen dalam keseluruhan kawasan isi objek yang hendak diukur (aspek representasi) dan sejauh mana aitem-aitem tes mencerminkan ciri perilaku yang hendak diukur (aspek relevansi) (Azwar, 2007). Uji validitas yang digunakan dalam penelitian ini adalah menggunakan rumus Corrected Item Total Correlation dengan bantuan SPSS 17 for windows. 
Konsep dari reliabilitas alat ukur adalah untuk mencari dan mengetahui sejauh mana hasil pengukuran dapat dipercaya. Reliabel dapat juga dikatakan keterpercayaan, keterhandalan, keajegan, kestabilan, konsistensi, dan sebagainya. Kecermatan data atau reliabilitas hasilnya akan banyak dipengaruhi oleh sikap, persepsi, dan motivasi responden dalam memberikan jawaban (Azwar, 2006). Reliabilitas dinyatakan dalam koefisien dengan angka antara 0 (nol) sampai 1,00 (satu). Semakin tinggi koefisien mendekati angka 1,00 (satu) berarti reliabilitas alat ukur semakin tinggi. Sebaliknya reliabilitas alat ukur yang rendah ditandai oleh koefisien reliabilitas yang mendekati angka 0 (nol) (Azwar, 2006). Dalam penelitian ini, uji reliabilitas menggunakan teknik Alpha Cronbach dengan menggunakan bantuan komputer program SPSS 17.00 for Windows. Azwar (2006) menyatakan bahwa pengolahan data penelitian yang sudah diperoleh dimaksudkan sebagai suatu cara mengorganisasikan data sedemikian rupa sehingga dapat dibaca (readable) dan dapat ditafsirkan (interpretabel). Teknik analisis yang digunakan untuk menganalisis data hasil penelitian ini adalah teknik korelasi Product Moment dari Pearson dengan menggunakan program SPSS 17 for windows. Uji normalitas digunakan untuk mengetahui apakah data terdistribusi dengan normal atau tidak. Korelasi Product Moment mensyaratkan bahwa data harus terdistribusi dengan normal, dan dalam hal ini digunakan Kolmogorov Smirnov Z. Uji linearitas bertujuan untuk mengetahui apakah dua variabel yang akan dikenai prosedur analisis statistik korelasional menunjukkan hubungan yang linier atau tidak. Jika $\mathrm{p}<0,05$ maka hubungan antara kedua variabel yaitu kualitas kehidupan kerja dan burnout dikatakan linier, dan sebaliknya jika $\mathrm{p}>0,05$ maka hubungan kedua variabel dikatakan tidak linier (Priyatno, 2010).

\section{Hasil dan Pembahasan}

Penelitian ini dilaksanakan di PT Multi Sarana Medan, Sumatera Utara. PT. Multi Saran Medan adalah perusahaan yang berada di Kota Medan tepatnya di Jalan Prof. HM Yamin No. 19 K, Sumatera Utara Indonesia. Merupakan salah satu perusahaan yang bergerak di bidang penyaluran / supply bahan bakar minyak industri yang telah berdiri sejak tahun 2002 di Medan, Sumatera Utara. PT Multi Sarana terus menerus mengembangkan bisnisnya yang sebelumnya hanya melakukan pendistribusian di sekitaran wilayah medan saja akan tetapi sekarang sudah mencapai pendistribusian di selurh seumatera utara. Bukan hanya fokus terhadap pengembangan bisnisnya sendiri, akan tetapi PT Multi Sarana sangat fokus untuk dapat melakukan pengembangan terhadap karyawannya sendiri. Uji coba skala dilakukan di perusahaan PT Samudra Sawit Subur pada tanggal 13 dan 14 juni 2019. Adapun subjek uji coba skala adalah karyawan PT. Samudra Sawit Transport yaitu diambil 70 orang yang telah bekerja di atas 3 tahun dalam populasi yang berbeda dengan subyek penelitian. Alasannya bahwa jumlah populasi terbatas, sehingga hanya sebagian yang bisa diambil sebagai subyek sampel uji coba, dengan harapan subyek uji coba mempunyai ciri-ciri dan karakteristik yang sama dengan subyek penelitian. Pada skala burnout, hasil analisis butir menunjukkan bahwa dari 35 dari 48 aitem dinyatakan sahih. Uji validitas menggunakan metode corrected item total correlation dimana aitem yang valid dengan nilai $r$ bergerak dari $0,322-0,731$. Dengan demikian dapat dinyatakan bahwa aitem yang gugur adalah sebanyak tujuh aitem. Tahap selanjutnya adalah melakukan pengujian reliabilitas dengan membuang aitem-aitem yang tidak valid terlebih dahulu. Teknik yang digunakan dalam menguji reliabilitas adalah teknik Cronbach Alpha. Dalam skala burnout ini diperoleh koefisien reliabilitas Cronbach Alpha sebesar 0.906. Hal ini dapat menunjukkan bahwa skala dalam uji coba ini layak digunakan sebagai alat pengumpulan data dalam penelitian nantinya. Pada skala kualitas kehidupan kerja, hasil analisis butir menunjukkan bahwa 36 dari 50 aitem dinyatakan sahih. Dalam uji validitas menggunakan metode corrected item total correlation dimana aitem yang valid dengan nilai $\mathrm{r}$ bergerak dari $0,305-0,739$. Tahap selanjutnya adalah melakukan pengujian reliabilitas dengan membuang aitem- aitem yang tidak valid terlebih dahulu.Pengujian reliabilitas dilakukan dengan menggunakan Teknik AlphaCronbach. Tinggi rendahnya reliabilitas, secara empiris ditunjukkan oleh suatu angka yang disebut koefisien reliabilitas, dalam skala kualitas kehidupan kerja ini diperoleh koefisien reliabilitas Alpha Cronbach= 0,920. Hal ini dapat menunjukkan bahwa skala dalam uji coba ini layak digunakan sebagai alat pengumpulan data dalam penelitian nantinya. Penelitian ini dilakukan pada tanggal 19, 20, dan 21 Juni 2019 pada 94 karyawan di PT. Multi Sarana Medan yang telah bekerja di atas 3 (tiga) tahun yang akan menjadi subjek penelitian. Skala burnout terdiri dari 35 aitem dengan skor aitemnya bergerak dari empat pilihan jawaban dengan skor satu sampai empat. Rentang maksimum dan minimumnya adalah $35 \times 1$ sampai $35 \times 4$, yaitu 35 sampai 140 dengan mean hipotetiknya $(35+140): 2=87.5$. Standar deviasi hipotetik dalam penelitian ini adalah (140-35) : $6=17.5$. Dari skala burnout yang diisi subjek, maka diperoleh mean empirik sebesar 106.54 dengan standar deviasi 10.094. Perbandingan data empiris dan data hipotesis dapat dilihat pada tabel 1.

Tabel 1. Perbandingan Data Empiris dan Hipotetik Burnout

\begin{tabular}{|c|c|c|c|c|c|c|c|c|}
\hline Variabel & & Empi & & & & Hipote & & \\
\hline Komitmen & Min & Max & Mean & SD & Min & Max & Mean & SD \\
\hline Organisasi & 75 & 128 & 106.54 & 10.094 & 35 & 140 & 87,5 & 17.5 \\
\hline
\end{tabular}


Hasil analisis untuk skala komitmen organisasi diperoleh mean empirik < mean hipotetik yaitu $106.54>87.5$ maka dapat disimpulkan bahwa burnout subjek penelitian menunjukkan kategori tinggi Selanjutnya subjek akan dibagi ke dalam tiga kategori burnout. Pengkategorian burnout dengan membagi distribusi normal ke dalam enam bagian standar deviasi yaitu: $\mathrm{x}<(\mu-1.0 \sigma)$ kategori rendah, $(\mu-1.0 \sigma) \leq \mathrm{x}<(\mu+1.0 \sigma)$ kategori sedang, $\mathrm{x} \geq(\mu+1.0$ $\sigma)$ kategori tinggi. Standar deviasi hipotetik dalam penelitian ini adalah $\sigma=(140-35): 6=17,5$ dan mean hipotetiknya adalah $\mu=(35+140): 2=87,5$. Dari perhitungan di atas dapat dibuat perhitungannya berdasarkan rumus yang telah diuraikan di atas, maka diperoleh $\mathrm{x}<(87,5-17,5)=70,(87,5-17,5)$

$\leq \mathrm{x}<(87,5+17,5)=70 \leq \mathrm{x}<105$, dan $\mathrm{x} \geq(87,5+17,5)=\mathrm{x} \geq 105$. Dari perhitungan di atas, dapat dibuat kategorisasi pada Tabel 2 berikut ini.

\begin{tabular}{|c|c|c|c|c|}
\hline \multicolumn{5}{|c|}{ Tabel 2. Kategorisasi Data Burnout } \\
\hline Variabel & Rentang Nilai & Kategori & Jumlah (n) & Persentase \\
\hline \multirow{4}{*}{ Burnout } & $x<70$ & Rendah & 0 & $0 \%$ \\
\hline & $70 \leq \mathrm{x}<105$ & Sedang & 38 & $40,5 \%$ \\
\hline & $x \geq 105$ & Tinggi & 56 & $59,5 \%$ \\
\hline & Jumlah & & 94 & $100 \%$ \\
\hline
\end{tabular}

Berdasarkan Tabel 2 dapat dilihat bahwa subjek burnout pada kategori rendah dan kategori sedang sebesar (0 persen), kategori sedang berjumlah 40 orang dengan perentase sebesar 40,5 persen sedangkan subjek burnout yang masuk dalam kategori tinggi berjumlah 59,5 persen orang dengan persentase sebesar 85,8 persen. Berdasarkan penjelasan di atas, maka dapat disimpulkan bahwa tidak ada subjek yang memiliki burnout yang rendah, seluruh subjek memiliki burnout yang dikategorikan sedang dan tinggi. Skala kualitas kehidupan kerja terdiri dari 38 aitem dengan skor aitemnya bergerak dari empat pilihan jawaban dengan skor satu sampai empat. Rentang maksimum dan minimumnya adalah $38 \times 1$ sampai $38 \times 4$, yaitu 38 sampai 152 dengan mean hipotetiknya ( $38+$ 152) $: 2=95$. Standar deviasi hipotetik dalam penelitian ini adalah $(152-38): 6=19$. Dari skala kualitas kehidupan kerja yang diisi subjek, maka dapat diperoleh mean empirik sebesar 111.69 dengan standar deviasi 8.060. Perbandingan data empiris dan data hipotesis dapat dilihat pada Tabel 3.

\begin{tabular}{|c|c|c|c|c|c|c|c|c|}
\hline \multirow{3}{*}{$\begin{array}{c}\text { Variabel } \\
\text { Kualitas } \\
\text { Kehidupan Kerja }\end{array}$} & \multicolumn{3}{|c|}{ Empirik } & \multirow[t]{2}{*}{ SD } & \multicolumn{3}{|c|}{ Hipotetik } & \multirow[t]{2}{*}{ SD } \\
\hline & Min & Max & Mean & & Min & Max & Mean & \\
\hline & 93 & 131 & 111.69 & 8.060 & 38 & 152 & 95 & 19 \\
\hline
\end{tabular}

Hasil analisis untuk skala kualitas kehidupan kerja diperoleh mean empirik > mean hipotetik yaitu 111.69>95 maka dapat disimpulkan bahwa kualitas kehidupan kerja pada subjek penelitian termasuk tinggi daripada populasi pada umumnya. Selanjutnya subjek akan dibagi ke dalam tiga kategori kualitas kehidupan kerja. Pengkategorian kualitas kehidupan kerja dengan membagi distribusi normal ke dalam enam bagian standar deviasi yaitu: $\mathrm{x}<(\mu-$ $1.0 \sigma)$ kategori rendah, $(\mu-1.0 \sigma) \leq x<(\mu+1.0 \sigma)$ kategori sedang, $x \geq(\mu+1.0 \sigma)$ kategori tinggi. Standar deviasi hipotetik dalam penelitian ini adalah $\sigma=(152-38): 6=19$ dan mean hipotetiknya adalah $\mu=(38+152): 2=95$. Dari perhitungan di atas dapat dibuat perhitungannya berdasarkan dengan rumus yang telah diuraikan di atas, diperoleh $\mathrm{x}<(95-19)=76,(95-19) \leq \mathrm{x}<(95+19)=76 \leq \mathrm{x}<114$, dan $\mathrm{x} \geq(95+19)=\mathrm{x} \geq 114$. Dari perhitungan di atas, dapat dibuat kategorisasi pada Tabel 3 berikut ini.

\begin{tabular}{ccccc}
\multirow{2}{*}{ Variabel } & \multicolumn{2}{c}{ Tabel 4. Kategorisasi Data Kualitas kehidupan kerja } \\
Rentang Nilai & Kategori & Jumlah (n) & Persentase \\
\hline \multirow{2}{*}{$\begin{array}{c}\text { Kualitas Kehidupan } \\
\text { Kerja }\end{array}$} & $\mathrm{x}<76$ & Rendah & 0 & $0 \%$ \\
\cline { 2 - 5 } & $76 \leq \mathrm{x}<114$ & Sedang & 56 & $59,6 \%$ \\
\cline { 2 - 5 } & $\mathrm{x} \geq 114$ & Tinggi & 38 & $40,4 \%$ \\
\hline
\end{tabular}

Berdasarkan kategori pada tabel 4, maka dapat dilihat kualitas kehidupan kerja pada subjek yang masuk dalam kategori rendah sebesar (0 persen), sedangkan kualitas kehidupan kerja pada subjek yang masuk dalam kategori sedang berjumlah 56 orang dengan persentase sebesar 59.6 persen dan subjek kategori tinggi berjumlah 38orang dengan persentase sebesar 40.4 persen. Berdasarkan penjelasan di atas, maka dapat disimpulkan bahwa tidak ada subjek yang memiliki kualitas kehidupan kerja rendah, seluruh subjek memiliki kualitas kehidupan kerja yang dikategorikan sedang dan tinggi. 
Uji normalitas dilakukan agar dapat mengetahui apakah setiap variabel dalam suatu penelitian telah menyebar secara normal. Uji normalitas sebaran menggunakan metode uji Kolmogorov Smirnov Test (K-SZ). Data dapat dikatakan berdistribusi normal jika p >0,05. Variabel kualitas kehidupan kerja menunjukkan nilai K-SZ sebesar 0.855 dengan Sig sebesar 0,457 untuk uji 2 (dua) ekor / Sig. 2-tailed, sedangkan penelitian ini memiliki hipotesis satu arah, sehingga yang dipakai adalah uji 1 (satu) ekor / Sig. 1-tailed sebesar 0,229(p > 0,05) yang artinya sebaran skor kualitas kehidupan kerja mengikuti distribusi normal. Variabel burnout menunjukkan nilai K-SZ sebesar 0.691 dengan Sig sebesar 0,726 untuk uji 2 (dua) ekor / Sig 2-tailed, dan untuk Sig. 1-tailed sebesar 0,363 (p > $0,05)$ artinya sebaran skor kualitas kehidupan kerja mengikuti distribusi normal. Berdasarkan hasil tersebut data pada variabel kualitas kehidupan kerja dan burnout memiliki sebaran atau berdistribusi normal karena $\mathrm{p}>0,05$. Hal tersebut dapat dilihat pada tabel 5.

Tabel 5. Hasil Uji Normalitas

\begin{tabular}{cccccc} 
Variabel & SD & K-SZ & Sig. & P & Keterangan \\
\hline Burnout & 10.094 & 0.691 & 0.726 & P $>0,05$ & Sebaran normal \\
\hline Kualitas Kehidupan Kerja & 8.060 & 0.855 & 0.457 & $\mathrm{P}>0,05$ & Sebaran normal
\end{tabular}

Uji linearitas digunakan untuk mengetahui apakah distribusi data penelitian yaitu variabel burnout dan kualitas kehidupan kerja memiliki hubungan linear. Variabel burnout dan kualitas kehidupan kerja dikatakan memiliki hubungan linear jika $\mathrm{p}<0,05$. Hal tersebut dapat dilihat pada Tabel 6 dibawah ini.

Tabel 6. Hasil Uji Linearitas Hubungan

\begin{tabular}{cccc} 
Variabel & F & Sig & Keterangan \\
\hline Burnout Kualitas Kehidupan Kerja & 177.320 & 0,000 & Linear $(\mathrm{P}<0,05)$
\end{tabular}

Berdasarkan Tabel 6 dapat dikatakan bahwa variabel burnout dan kualitas kehidupan kerja memiliki hubungan linear. Hal ini terlihat dari nilai $\mathrm{P}$ yang diperoleh yaitu 0,000 maka $\mathrm{p}<0,05$ maka dapat disimpulkan adalah kedua variabel memiliki hubungan linear dan telah memenuhi syarat untuk dilakukan analisa korelasi Product Moment.

Setelah uji asumsi diterima selanjutnya dilakukan uji hipotesis. Hipotesis dalam penelitian ini adalah ada hubungan positif antara burnout dengan kualitas kehidupan kerja. Pengujian hipotesis dilakukan dengan menggunakan teknik analisis Pearson Correlation. Hasil uji statistik dapat dilihat pada Tabel 7.

Tabel 7. Korelasi antara burnout dengan Kualitas kehidupan Kerja

\begin{tabular}{ccc} 
Analisis & $\begin{array}{c}\text { Pearson } \\
\text { Correlation }\end{array}$ & $\begin{array}{c}\text { Signifikansi } \\
(\mathrm{p})\end{array}$ \\
\hline Korelasi & -0.839 & 0,000 \\
\hline
\end{tabular}

Berdasarkan hasil analisis korelasi antara kualitas kehidupan kerja dan burnout, diperoleh koefisien korelasi product moment sebesar -0.839 dengan $\mathrm{p}$ sebesar 0,000 ( $\mathrm{p}<0,05$ : Sig. 1-tailed). Hal ini menunjukkan bahwa adanya korelasi negatif antara burnoutdengan kualitas kehidupan kerja. Dari hasil perhitungan tersebut, maka hipotesis yang diajukan dalam penelitian ini menunjukkan adanya hubungan yang negatif antara burnout dengan kualitas kehdupan kerja dinyatakan dapat diterima. Dengan demikian dapat disimpulkan bahwa semakin tinggi kualitas kehidupan kerja, maka semakin rendahburnout dan sebaliknya semakin rendah kualitas kehidupan kerja maka semakin tinggi kualitas kehidupan kerja karyawan. Hasil penelitian pada 94 karyawan di PT Multi Sarana Medan yang menjadi subjek penelitian diperoleh hasil bahwa ada hubungan negatif antara kualitas kehidupan kerja dengan burnout dengan koefisien korelasi product moment sebesar $\mathrm{r}=-0,839$ nilai p sebesar $0,000(\mathrm{P}<$ 0,05), artinya semakin tinggi kualitas kehidupan kerja maka semakin rendah burnout sebaliknya semakin rendah kualitas kehidupan kerja maka semakin tinggi burout. 
Senada juga dengan penelitian terdahulu yang dilakukan oleh Zanganeh dan Aghaei (2013), terhadap 206 subjek. Hasil penelitian tersebut menunjukkan bahwa terdapat hubungan yang signifikan negatif antara kualitas kehidupan kerja dengan burnout $(\mathrm{r}=-0,477)$ yang menunjukkan semakin tinggi kualitas kehidupan kerja seorang karyawan dimana karyawan tersebut memiliki kondisi kerja yang aman dan sehat yang tidak membahayakan fisik dan kesehatan mereka, memiliki waktu kerja yang sesuai dengan yang telah ditetapkan dan umur yang sesuai dengan pekerjaan yang seharusnya maka karyawan tersebut akan rendah untuk dapat terkena sindrom burnout dan sebaliknya apabila semakin rendah kualitas kehidupan kerja maka semakin tinggi burnout.

\section{Kesimpulan}

Berdasarkan hasil-hasil yang telah diperoleh dalam penelitian ini, maka dapat disimpulkan, ada hubungan negatif antara burnout dengan kualitas kehidupan kerja pada karyawan di PT. Multi Sarana dengan korelasi Product Moment (r) -0,839 dengan p sebesar 0,000 maka p < 0,05, artinya semakin tinggi burnout maka semakin rendah kualitas kehidupan kerja, dan sebaliknya jika semakin rendah burnout maka semakin tinggi kualitas kehidupan kerja. Mean dari burnout pada subjek penelitian karywan PT Multi Sarana secara keseluruhan menunjukkan bahwa perilaku burnout pada subjek penelitian berada pada kategori tinggi. Mean dari kualitas kehidupan kerja pada subjek karyawan di PT Multi Sarana secara keseluruhan menunjukkan bahwa kualtias kehidupan kerja subjek penelitian menunjukkan kategori sedang. Hasil penelitian ini menunjukkan bahwa sumbangan yang diberikan variabel burnout terhadap kualitas kehidupan kerja adalah sebesar 70,3 persen, selebihnya 29,7 persen dipengaruhi oleh faktor lain.

\section{Daftar Rujukan}

[1] Yuhefizar, Santosa B., Eddy I. K. P, and Suprapto Y. K, 2013, Combination of Cluster Method for Segmentation of Web Visitors. TELKOMNIKA, 11(1), pp. 207-214. doi: http://dx.doi.org/10.12928/telkomnika.v11i1.906.

[2] Na`am J., Harlan J., Madenda S., and Wibowo E. P. 2016. Identification of the Proximal Caries of Dental X-Ray Image with Multiple Morphology Gradient Method. International Journal on Advanced Science, Engineering and Information Technology (IJASEIT), 6(3), pp. 343-346. doi:10.18517/ijaseit.6.3.827.

[3] Na`am J., 2017. Edge Detection on Objects of Medical Image with Enhancement multiple Morphological Gradient (EmMG) Method. 4th Proc. EECSI. 23-24 Sep. 2017. Yogyakarta: Indonesia. doi=10.1109/EECSI.2017.823908

[4] Arikunto,S., 2010. Prosedur Penelitian, Suatu pendekatan praktik. Jakarta: PT. Rineka Cipta.

[5] Azwar, S., 2006. Penyusunan Skala Psikologi. Edisi 1, Cetakan ke 8. Yogyakarta :Pustaka Pelajar.

[6] Habibah, D. Y. \& Lubis, R., 2015. Jurnal Psikologi. Hubungan Antara Kualitas Kehidupan Kerja Dengan Burnout Syndrom Pada Karyawan PT. Surya Alam Permaidi Palembang, 10 (03)

[7] Hariandja, M. T. E. 2002. Manajemen SDM :Pengadaan, Pengembangan, Pengkompensasian dan Peningkatan Produktifitas Pegawai.Jakarta PT. GramediaWidiasarana Indonesia.

[8] Koran sindo, 2018. Diduga Stress Kerja, Karyawati Bank Bunuh Diri [Online] (Updated 09 Jan 2018) Tersedia di : http://www.koran-sindo.com [Accessed 15 Maret 2019]

[9] Martono,N., 2011. Metode penelitian kuantitatif analisis isi dan analisis data skunder. Jakarta. PT Raja GrafindoPersada

[10] Maslach, C. \& Leiter, M. P., 1997. The Truth About Burnout: How Organization Cause Personal Stress and What To Do About It [Ebook] (Updated 01 Jan 2017)Tersedia di:

https://trove.nla.gov.au/work/15969531?selectedversion=NBD13241490[Accessed 09 Oktober 2019]

[11] Schabracq, M. J., Winnubst, J. A. M., \& Cooper, C., L. 2003.The Handbook of Work and Health Psychology. Second Edition [E-book] (Updated 08 Mar 2016)

Tersedia di: https://www.bookzz.org [Accessed 08 Oktober 2019]

[12] Soewadji, J., 2012. Pegantar Metodologi Penelitian. Jakarta: Witra Wacana Media.

[13] Tuuli, P. \& Karisalmi, S., 2010. An International Journal Devoted to the Scientific Study of the Aging Process. Impact of Working Life Quality on Burnout, 25 (4)

[14] Vandenberghe, R. \& Huberman, A. M., 2006. Understanding and Preventing Teacher Burnout. NewYork: The Cambridge University Press

[15] Ventegodt,S. \& Merrick. 2009 . Health and Happiness from Meaningful Work Research in Quality Of Working Life. [E-book] (Updated 08 Mar 2016) 